\title{
Gonococcal infections and emergence of gonococcal decreased susceptibility to cephalosporins in France, 2001 to 2012
}

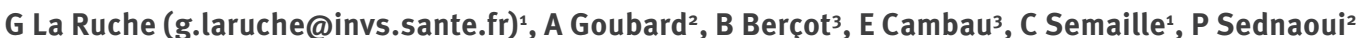

1. French Institute for Public Heath Surveillance, Department of infectious diseases, Saint-Maurice, France

2. Institut Alfred Fournier, National Reference Laboratory for gonorrhoea, Paris, France

3. Laboratory of Bacteriology, Virology and Hygiene, Saint-Louis/Lariboisière/Fernand Widal hospitals, National Reference associated Laboratory for Gonorrhoea, Paris, France

Citation style for this article:

La Ruche G, Goubard A, Berçot B, Cambau E, Semaille C, Sednaoui P. Gonococcal infections and emergence of gonococcal decreased susceptibility to cephalosporins in France, 2001 to 2012. Euro Surveill. 2014;19(34):pii=20885. Available online: http://www.eurosurveillance.org/ViewArticle.

aspx?Articleld=20885

Article submitted on 13 September 2013 / published on 28 August 2014

Resistance to cephalosporins may lead to untreatable gonococcal infections. We describe the results of the sentinel surveillance of gonococcal infections and the evolution of the resistance of Neisseria gonorrhoeae to antibiotics in France from 2001 to 2012. We also analyse the factors associated with decreased susceptibility to third generation cephalosporins. In France, surveillance of gonococcal infections is conducted through a network of voluntarily participating laboratories. Strains are sent to the national reference laboratory to determine the minimum inhibitory concentration (MIC) for six antibiotics. During the study period, the number of gonococcal infections increased steadily. The susceptibility of 8,649 strains was studied for this period. The proportion of strains with decreased susceptibility to cefixime (MIC>0.125 mg/L) quadrupled between 2011 (0.7\%:10/1,521) and 2012 (3.0\%: 33/1,093; p<0.001). Between 2001 and 2012, only two of the 8,649 strains, both collected in 2010 , had a MIC>0.125 mg/L for ceftriaxone. Decreased susceptibility to cephalosporins increased with older age and was more common in pharyngeal strains. Decreased susceptibility to cefixime may indicate that the national recommendation to use ceftriaxone as a first line treatment for cases of urethritis and cervicitis has not been fully implemented. Enhanced surveillance of pharyngeal strains is strongly suggested.

\section{Introduction}

Although gonorrhoea is a common sexually transmitted infection (STI), normally responsible for uncomplicated genital infections, the disease can sometimes lead to severe complications (salpingitis, epididymoorchitis, septicaemia) [1,2]. It also increases the risk of transmission by human immunodeficiency virus (HIV) [2]. Because of its short incubation time (mainly 2 to 5 days) [3] and characteristic symptoms in men, the incidence of gonorrhoea can be used as a very sensitive indicator of the relaxation of safe sexual behaviours, and as an early warning signal for increased risk of HIV transmission [2].

Following acquired immunodeficiency syndrome (AIDS) prevention campaigns in the 1980 s and at the beginning of the 1990s, the number of cases of gonorrhoea in certain European Union (EU) and European Free Trade Association (EFTA) countries [4], including France [5], dropped significantly. This drop was the result of a reduction of at-risk sexual behaviours [6]. The advent of antiretroviral multitherapy in the mid-1990s brought with it a resurgence of these behaviours in the general population, especially in men who have sex with men (MSM). It also led to a resurgence in cases of gonorrhoea in some EU/EFTA countries $[5,6]$ as well as in the United States [7].

In France, the epidemiological surveillance of gonorrhoea is based on two voluntary sentinel networks relying on clinicians (the RésIST network) or public and private laboratories (the Rénago network - National Gonorrhoea Network -) $[8,9]$. Since the beginning of the 2000s, an increase in gonococcal infections has been observed by these networks, both in men and women [9]. The RésIST network also highlighted that this increase exists irrespective of sexual orientation $[8,9]$.

At the end of the 1990s and the beginning of the 2000s, concomitantly with the resurgence of gonoccocal infections, several countries reported increasing levels of gonococcal resistance to ciprofloxacin $[2,10]$, a fluoroquinolone antibiotic, which was used at the time as a single-dose first-line treatment for uncomplicated urogenital gonorrhoea. Since the mid-200os, singledose third generation cephalosporins (TGC), specifically oral cefixime and injectable ceftriaxone, became the only remaining recommendable antimicrobial class [11]. These treatments were officially recommended 
Geographical distribution of the 133 laboratories in the Rénago ${ }^{a}$ network according to participation in microbiological surveillance, France, 2012

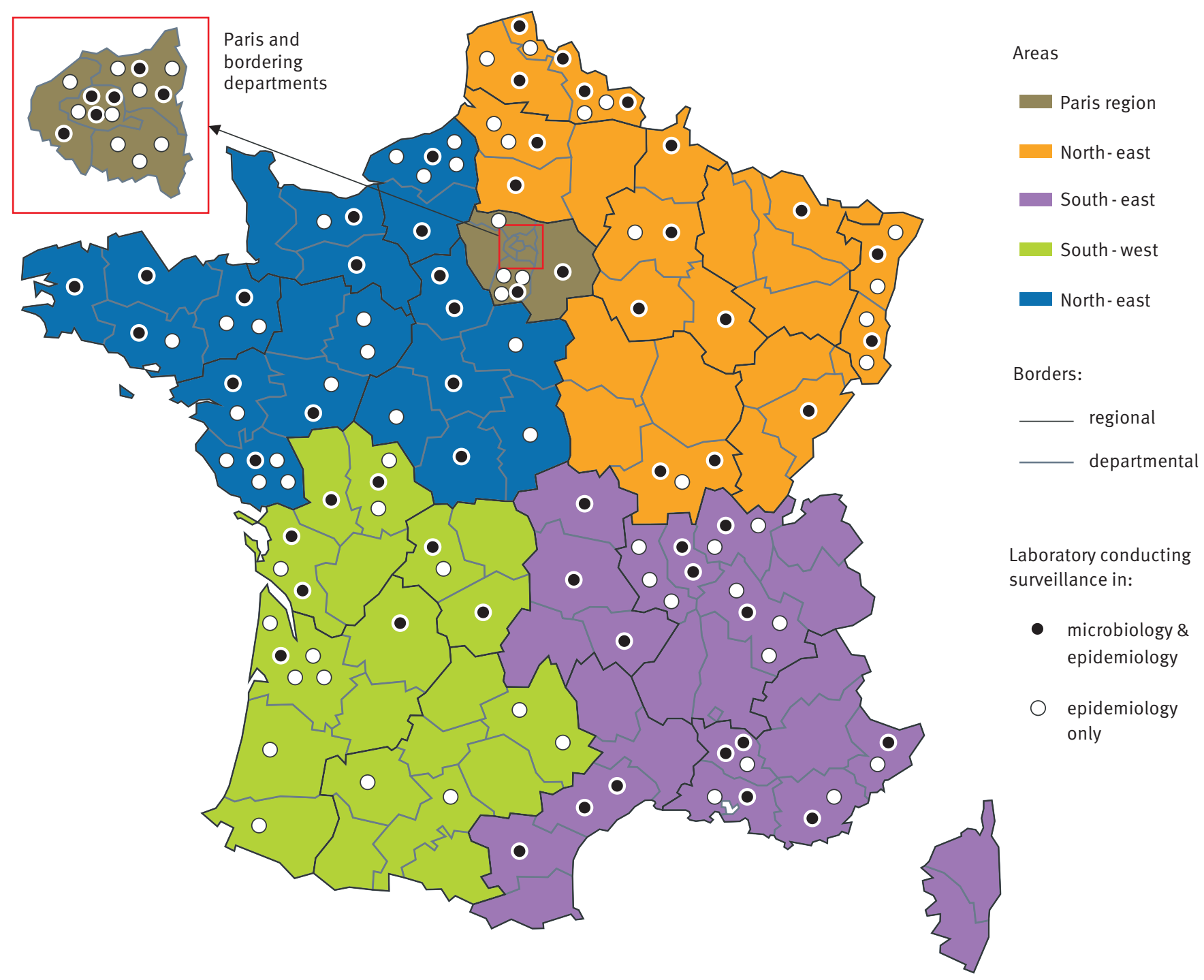

a Rénago is the national gonorrhoea network, a sentinel network based on voluntarily participating public and private laboratories.

in France at the end of 2005 [12]. However, the subsequent development of clinical and biological resistance to TGC, especially to cefixime, and, since the end of the 200os, to ceftriaxone, may lead to a therapeutic dead end in the coming years $[2,11]$. Surveillance of gonococcal susceptibility to these antibiotics is therefore essential.

Given this worrying context, the objective of this study was to describe the evolution of gonococcal infections and the changes in the susceptibility of gonorrhoea strains to antibiotics in France between 2001 and 2012. Factors associated with decreased susceptibility to TGC are also assessed.

\section{Methods}

The laboratories in the Rénago network are distributed throughout all of metropolitan France. This network helps monitor the resistance of Neisseria gonorrhoeae strains to antibiotics. Laboratory participation to surveillance is voluntary.

The laboratories receive patients referred by their doctor who prescribed a microbiological diagnosis for gonorrhoea. An anonymous epidemiological file, collected by the network laboratory microbiologist, provided the following information for each patient: sex, age, date of sample, anatomical site of sample, presence of symptoms, co-infection with another STI, probable country of infection, information on partner's infection, the place of consultation and specialisation of treating physician, type of laboratory and geographical area to which it belongs. The sexual orientation of the patient is not reported. Information is consolidated and analysed by the Institut de Veille Sanitaire (InVS). 
Because of the large proportion of missing data for four variables (presence of symptoms, co-infection with another STI, probable country of infection, and information on patient's partner infection status), the latter were used only for univariate analysis for descriptive purposes. All other variables were included in the multivariate analysis; p<0.05 was used as the level for significance. Only the results of multivariate analysis are presented here, unadjusted and adjusted odds-ratios being very similar. For the analyses, the data concerning the years from 2001 to 2009 were pooled to highlight recent developments of the characteristics of gonococcal infections and of antibiotic susceptibility of strains in the period from 2010 to 2012.

Gonococcal infection is laboratory confirmed by a positive culture or a positive nucleic-acid amplification test (NAAT) for N. gonorrhoeae by the network laboratories. Strains isolated by culture by the network laboratories are sent for antibiotic susceptibility testing to the Alfred Fournier Institute in Paris, which is the national reference laboratory (NRL) for gonorrhoea.

Because of the very high number of strains received by the NRL as well as budget constraints, the InVS and the NRL decided to separate epidemiological and microbiological surveillance. Although the epidemiological data collection continued for all laboratories in the network, the number of laboratories sending their strains to the NRL was reduced by about fifty per cent from the beginning of January 2012 (in 2012, 63 of the 133 laboratories in the network participated to the microbiological surveillance). Nevertheless, a homogeneous geographical distribution of laboratories continuing this microbiological surveillance was ensured (Figure 1).

The NLR determines the minimum inhibitory concentration (MIC) for six antibiotics (penicillin G, tetracycline, ciprofloxacin, spectinomycin, ceftriaxone, and, since 2008, cefixime) using Etest strips (first from $A B$ Biodisk, Solna, Sweden; then from AES Laboratory, Combourg, France, and from May 2011 from i2a, Pérols, France). These antibiotics were or are still recommended for the treatment of gonorrhoea [11]. The presence of beta-lactamases is detected using Api NH (bioMérieux, Marcy-l'Etoile, France) identification test kits and, when there is any doubt, using a chromogenic cephalosporin test (cefinase, bioMérieux). The criteria used to define resistance are those used by the European Committee on Antimicrobial Susceptibility Testing -EUCAST 2013 [13]. For TGC, no defined threshold exists for resistance; strains with a MIC>0.125 mg/L for cefixime and for ceftriaxone are regarded as having a decreased susceptibility. A strain was considered multi-resistant if it was resistant to penicillin $\mathrm{G}$, tetracycline and ciprofloxacin, and if the MIC for cefixime or for ceftriaxone was $>0.125 \mathrm{mg} / \mathrm{L}$.

The factors associated with a reduction in susceptibility of gonorrhoea to TGC in patients aged at least 15 years-old were determined through univariate and
FIGURE 2

Annual number of reported gonococcal infections and strains tested by the national reference laboratory for gonorrhoea, Rénago network ${ }^{a}$, France, 2001-2012

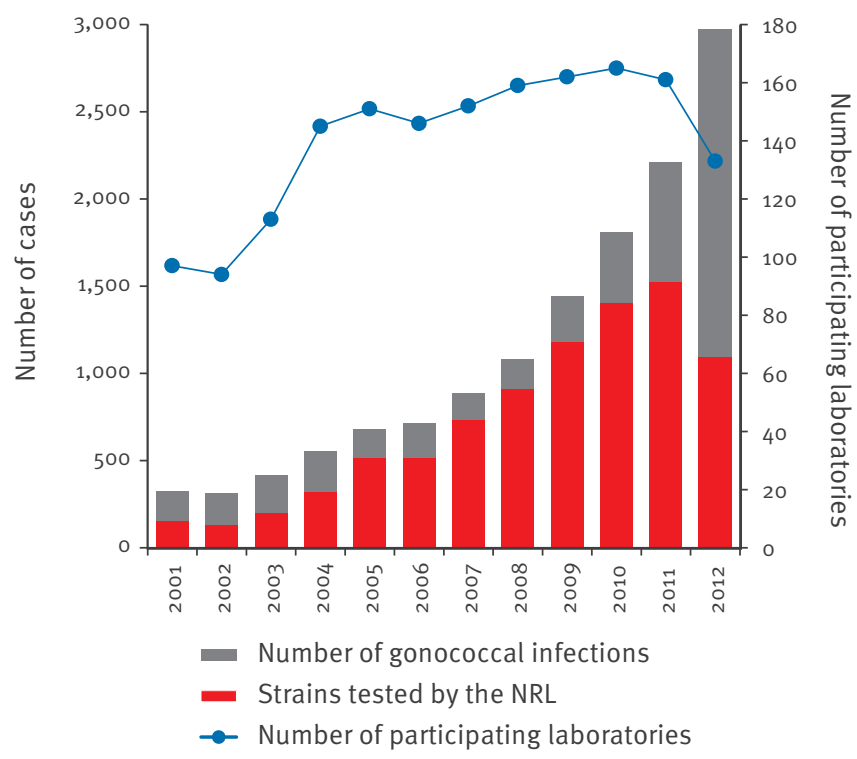

NRL: national reference laboratory.

a Rénago is the national gonorrhoea network, a sentinel network based on voluntarily participating public and private laboratories. All laboratories participate to the epidemiological surveillance. Until 2011, all laboratories participated to the microbiological surveillance. In 2012, only 63 of the 133 laboratories of the network participated to the microbiological surveillance.

multivariate analyses using Stata v.11.0 software, excluding missing values. As the number of strains with MIC>0.125 mg/L for TGC was low, we studied the factors associated with a MIC $\geq 0.094 \mathrm{mg} / \mathrm{L}$ for cefixime and $\mathrm{a} M I C \geq 0.032 \mathrm{mg} / \mathrm{L}$ for ceftriaxone. These values were chosen arbitrarily to have a sufficient number of strains with MICs above these cut-offs to allow comparison analyses. Taking into account such cut-offs, $6 \%$ of strains had decreased susceptibility to these two antibiotics.

\section{Results}

\section{Evolution of the number of gonococcal infections and analysed strains}

Between 2001 and 2012, 13,400 cases of gonorrhoea were reported by the network's laboratories. From these cases, a total of 10,501 strains were sent to the NLR. The NLR succeeded in recultivating $8,649(82 \%)$ of them to determine the susceptibility of $N$. gonorrhoeae to antibiotics. The proportion of strains sent to the NLR and then recultivated remained quite stable from 2005 to 2012 ( $84 \%$ on average for this period, range 82 to $87 \%)$.

Figure 2 shows the increase in the number of reported cases and the number of strains studied by the NLR 
TABLE 1

Characteristics of cases of gonorrhoea, Rénago ${ }^{a}$ network, France 2001-2012 (n=13,400)

\begin{tabular}{|c|c|c|c|c|c|}
\hline Variables & $\begin{array}{c}2001-2009 \\
N(\%)\end{array}$ & $\begin{array}{l}2010 \\
\mathrm{~N}(\%)\end{array}$ & $\begin{array}{r}2011 \\
\text { N (\%) }\end{array}$ & $\begin{array}{l}2012 \\
\mathrm{~N}(\%)\end{array}$ & $\begin{array}{c}\text { Total } 2001-2012 \\
\text { N (\%) }\end{array}$ \\
\hline Total & $6,407(100)$ & $1,807(100)$ & $2,211(100)$ & $2,975(100)$ & $13,400(100)$ \\
\hline \multicolumn{6}{|l|}{ Sex } \\
\hline Male & $5,552(87)$ & $1,506(83)$ & $1,718(78)$ & $2,044(69)$ & $10,820(81)$ \\
\hline Female & 846 (13) & $299(17)$ & $493(22)$ & $928(31)$ & 2,566 (19) \\
\hline Not provided & $9(41)$ & $2(41)$ & $\mathrm{o}(\mathrm{o})$ & $3(41)$ & $14((1)$ \\
\hline \multicolumn{6}{|l|}{ Age (in years) } \\
\hline $0-14$ & $12((1)$ & $8(\measuredangle 1)$ & $5((1)$ & $21(1)$ & $46((1)$ \\
\hline $15-24$ & $1,838(29)$ & $673(37)$ & $916(41)$ & $1,387(47)$ & $4,814(36)$ \\
\hline $25-34$ & $2,323(36)$ & $598(33)$ & 687 (31) & $904(30)$ & $4,512(34)$ \\
\hline $35-44$ & $1,318(21)$ & 305 (17) & $318(14)$ & 347 (12) & $2,288(17)$ \\
\hline$\geq 45$ years & 688 (11) & $180(10)$ & $228(10)$ & 254 (9) & $1,350(10)$ \\
\hline Not provided & $228(4)$ & $43(2)$ & $57(3)$ & $62(2)$ & $390(3)$ \\
\hline \multicolumn{6}{|l|}{ Anatomical site } \\
\hline Urethra or urine & $4,905(77)$ & $1,394(77)$ & $1,598(72)$ & $1,972(66)$ & 9,869 (74) \\
\hline Cervix or vagina & $745(12)$ & 278 (15) & $459(21)$ & $839(28)$ & $2,321(17)$ \\
\hline Anus & 588 (9) & $98(5)$ & $105(5)$ & $77(3)$ & $868(6)$ \\
\hline Pharynx & $35(1)$ & $8(\ll 1)$ & $23(1)$ & $33(1)$ & $99(1)$ \\
\hline Other sites & $112(2)$ & $24(1)$ & $25(1)$ & $35(1)$ & 196 (1) \\
\hline Not provided & $22((1)$ & $5(\ll 1)$ & $1(\ll 1)$ & $19(1)$ & $47((1)$ \\
\hline \multicolumn{6}{|l|}{ Presence of symptoms } \\
\hline Yes & $4,336(68)$ & $1,099(61)$ & $1,365(62)$ & $1,739(58)$ & $8,539(64)$ \\
\hline No & $127(2)$ & $97(5)$ & $93(4)$ & $160(5)$ & $477(4)$ \\
\hline Not provided & $1,944(30)$ & $611(34)$ & $753(34)$ & $1,076(36)$ & $4,384(33)$ \\
\hline \multicolumn{6}{|l|}{ Co-infection with another STI } \\
\hline Yes & $951(15)$ & $287(16)$ & 425 (19) & $715(24)$ & $2,378(18)$ \\
\hline No & $1,941(30)$ & $437(24)$ & $568(26)$ & $868(29)$ & $3,814(28)$ \\
\hline Not provided & $3,515(55)$ & $1,083(60)$ & $1,218(55)$ & $1,392(47)$ & $7,208(54)$ \\
\hline \multicolumn{6}{|l|}{ Probable country of infection } \\
\hline France & $1,691(26)$ & $502(28)$ & $576(26)$ & $719(24)$ & $3,488(26)$ \\
\hline Abroad & $134(2)$ & $27(1)$ & $35(2)$ & $27(1)$ & $223(2)$ \\
\hline Not provided & $4,582(72)$ & $1,278(71)$ & $1,600(72)$ & $2,229(75)$ & $9,689(72)$ \\
\hline \multicolumn{6}{|l|}{ Patient's partner infected } \\
\hline Yes & $212(3)$ & $76(4)$ & $102(5)$ & $124(4)$ & $514(4)$ \\
\hline No & $122(2)$ & $38(2)$ & $47(2)$ & $90(3)$ & $297(2)$ \\
\hline Not provided & $6,073(95)$ & $1,693(94)$ & $2,062(93)$ & $2,761(93)$ & $12,589(94)$ \\
\hline \multicolumn{6}{|l|}{ Place of consultation } \\
\hline Private sector or clinic & $3,410(53)$ & $1,175(65)$ & $1,425(64)$ & $1,581(53)$ & $7,591(57)$ \\
\hline Hospital & $1,203(19)$ & $274(15)$ & $316(14)$ & $462(16)$ & 2,255 (17) \\
\hline Specialised facilities for STIs ${ }^{b}$ & $831(13)$ & $321(18)$ & $398(18)$ & $751(25)$ & $2,301(17)$ \\
\hline Other structures & $\mathrm{o}(\mathrm{o})$ & $9(\ll 1)$ & $47(2)$ & $93(3)$ & $149(1)$ \\
\hline Not provided & $963(15)$ & $28(2)$ & $25(1)$ & $88(3)$ & $1,104(8)$ \\
\hline \multicolumn{6}{|l|}{ Prescribing doctor } \\
\hline General practitioner & $3,660(57)$ & $1,260(70)$ & $1,458(66)$ & $1,814(61)$ & $8,192(61)$ \\
\hline Gynaecologist & $634(10)$ & $156(9)$ & $262(12)$ & $386(13)$ & $1,438(11)$ \\
\hline Dermatologist-venereologist & $860(13)$ & $100(6)$ & $86(4)$ & $168(6)$ & $1,214(9)$ \\
\hline Other medical specialisation & $877(14)$ & $256(14)$ & $320(14)$ & $381(13)$ & $1,834(14)$ \\
\hline Not provided & $376(6)$ & $35(2)$ & $85(4)$ & $226(8)$ & $722(5)$ \\
\hline \multicolumn{6}{|l|}{ Type of Laboratory } \\
\hline Private & $4,612(72)$ & $1,376(76)$ & $1,617(73)$ & $1,984(67)$ & $9,589(72)$ \\
\hline Hospital & $1,610(25)$ & $352(19)$ & $500(23)$ & $804(27)$ & $3,266(24)$ \\
\hline Community clinic & $185(3)$ & $79(4)$ & $94(4)$ & $187(6)$ & $545(4)$ \\
\hline \multicolumn{6}{|c|}{ Laboratory location (area in France) } \\
\hline Paris region & $2,820(44)$ & $677(37)$ & $751(34)$ & $1,021(34)$ & 5,269 (39) \\
\hline North-west & $1,119(17)$ & $421(23)$ & $508(23)$ & $672(23)$ & $2,720(20)$ \\
\hline North-east & 966 (15) & $304(17)$ & $384(17)$ & $412(14)$ & $2,066(15)$ \\
\hline South-east & $938(15)$ & $232(13)$ & $332(15)$ & $494(17)$ & $1,996(15)$ \\
\hline South-west & $564(9)$ & $173(10)$ & $236(11)$ & $376(13)$ & $1,349(10)$ \\
\hline
\end{tabular}

STI: sexually transmitted infection.

${ }^{a}$ Rénago is the national gonorrhoea network, a sentinel network based on voluntarily participating public and private laboratories.

b Specialised facilities for the management of STI: STI clinics, free anonymous counselling and testing services and family planning centres. 
between 2001 and 2012. During the first five years of the study, the number of laboratories participating in epidemiological surveillance greatly increased, from 97 in 2001 to 151 in 2005. This number subsequently remained quite stable before decreasing between $2011(n=161)$ and $2012(n=133)$. The yearly number of strains whose susceptibility was examined by the NLR increased tenfold from 150 in 2001 to 1,521 in 2011. In 2012 , with the number of participating laboratories to the microbiological surveillance decreasing by half, 1,093 strains were tested.

Since 2009, larger numbers of diagnoses are being made using NAAT. NAAT accounted for only $6 \%$ $(84 / 1,444)$ of microbiological diagnoses of gonorrhoea in 2009 , this figure increased to $13 \%(237 / 1,807)$ in 2010, $25 \%(554 / 2,211)$ in 2011 and $47 \%(1,408 / 2,975)$ in 2012. NAAT was exclusively used to diagnose gonorrhoea in $3 \%(40 / 1,444), 8 \%(136 / 1,807), 14 \%$ $(302 / 2,211)$ and $28 \%(839 / 2,975)$ of patients, for each of these years, respectively (pro.001, chi-square test for trend).

\section{Epidemiological and clinical characteristics of cases of gonorrhoea}

The clinical characteristics of reported cases of gonorrhoea are shown in Table 1. Most were male $(81 \%$ over the whole study period: $10,820 / 13,400$ ), yet the proportion of female constantly increased, reaching $31 \%(928 / 2,975)$ of cases in 2012 . The 15 - to 24 -yearold age group was most affected, and saw a constant increase over time for both sexes. Median age was higher in men (29 years compared with 22 years in women; p<o.001, analysis of variance) over the whole study period, but decreased over time both in men and women (from, respectively, 30 and 24 years between 2001 and 2009, to 26 and 21 years in 2012; p<0.001 for both comparisons).

Information on the presence of symptoms was missing for $33 \%(4,384 / 13,400)$ of cases. Considering those with such information available, $98 \%(7,587 / 7,720)$ of men and $73 \%(942 / 1,285)$ of women presented with symptoms (p<0.001). Information on simultaneous infection with another STI was missing in $54 \%$ $(7,208 / 13,400)$ of cases. For cases with data, $32 \%$ $(1,456 / 4,622)$ of men and $59 \%(918 / 1,561)$ of women had another STI ( $p<0.001)$, mainly co-infection with chlamydia (19\%: 862/4,622 of co-infection in men and 48\%: 744/1,561 in women; p<0.001). Information on probable country of infection (i.e. in France or abroad) was missing in $72 \%(9,689 / 13,400)$ of cases. When it was available, infection had occurred outside of France in $7 \%(206 / 3,146)$ and $3 \%(17 / 561)$ of men and women, respectively $(p=0.001)$. The partner's infection status was hardly ever recorded by the laboratories, as the information was missing for $94 \%(12,589 / 13,400)$ of cases.

In men, samples were taken mainly from the urethra or urine $(90 \%: 9,741 / 10,820)$. Samples from the anus
( $8 \%: 842 / 10,820$ over the whole study period, diminishing in recent years to $4 \%: 72 / 2,044$ in 2012) and pharynx (1\%: 93/10,820) were much rarer. In women, samples were taken mainly from the cervix or vagina (90\%: 2,320/2,566). Urethral (5\%: 119/2,566) and anal (1\%: 24/2,566) samples were also much rarer.

Patients had mainly consulted in private general practitioner offices or in clinics $(67 \%: 6,588 / 9,859$ and $41 \%: 1,000 / 2,424$ of the men and women, respectively, for whom information was available; pro.001). Consultation had occurred less frequently in hospitals (17\%: 1,632/9,859 and 26\%: $621 / 2,424$ of men and women, respectively; p<0.001) and less frequently in the following specialised facilities: STI clinics, free Anonymous Counselling and Testing Services and Family Planning Centres (15\%: $1,521 / 9,859$ and $32 \%$ : $772 / 2,424$ of men and women, respectively; p<0.001). The prescribing doctor was a general practitioner in most cases ( $71 \%: 7,236 / 10,244$ of men and 39\%: $950 / 2,421$ of women for whom information was available; p 0.001 ), a gynaecologist ( $50 \%: 1,209 / 2,421$ of women) or a specialist in dermato-venereology $(11 \%$ : $1,127 / 10,244$ and $3 \%: 83 / 2,421$ of men and women, respectively; $p<0.001)$.

Finally, bacteriological samples were mainly taken in private laboratories ( $74 \%: 7,992 / 10,820$ of men and $62 \%: 1,586 / 2,566$ of women; p<o.001). They were less frequently collected in hospital laboratories $(22 \%$ : 2,384/10,820 and 34\%: 879/2,566 of men and women, respectively; p $<0.001)$ and rarely at a community clinic ( $4 \%$ of men: 444/10,820 and of women: 101/2,566; $\mathrm{p}=0.70)$.

\section{FIGURE 3}

Evolution of the resistance of gonococcal strains to penicillin G, tetracycline and ciprofloxacin, Rénago ${ }^{\mathrm{a}}$ network, 2001-2012 ( $\mathrm{n}=8,649$ strains)

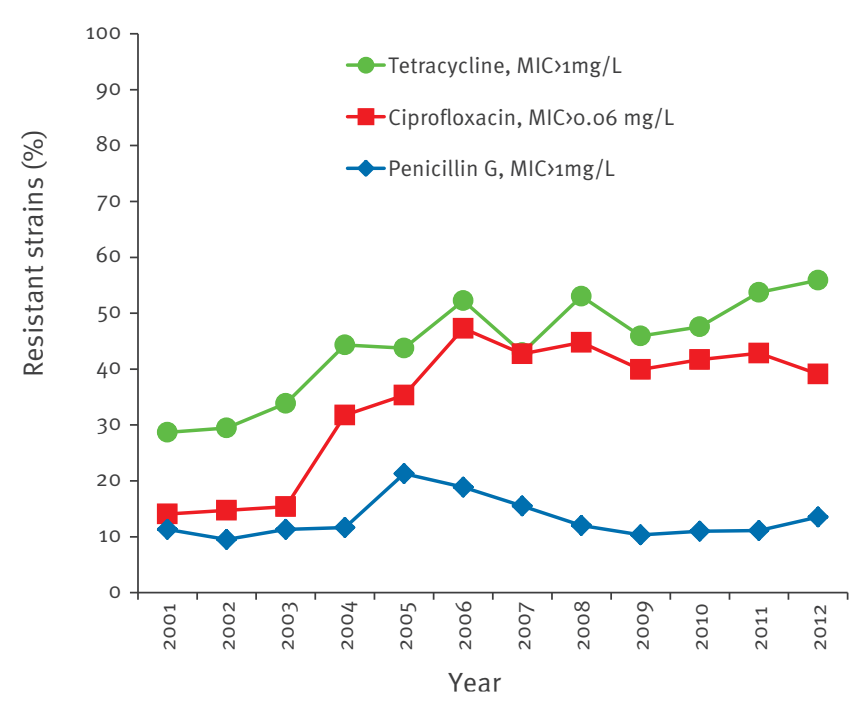

MIC: minimum inhibitory concentration.

a Rénago is the national gonorrhoea network, a sentinel network based on voluntarily participating public and private laboratories. 
TABLE 2

Evolution of the susceptibility of gonoccocal strains to antibiotics, Rénago network ${ }^{\mathrm{a}}, 2001-2012$ (n=8,649 strains)

\begin{tabular}{|c|c|c|c|c|}
\hline Antibiotics & $\begin{array}{c}2001-2009 \\
N(\%)\end{array}$ & $\begin{array}{l}2010 \\
\text { N (\%) }\end{array}$ & $\begin{array}{l}2011^{b} \\
N(\%)\end{array}$ & $\begin{array}{l}2012 \\
\text { N (\%) }\end{array}$ \\
\hline \multicolumn{5}{|l|}{ Penicillin G } \\
\hline Susceptible strains (MIC $\leq 0.064 \mathrm{mg} / \mathrm{L})$ & $1,251(27)$ & $383(27)$ & $130(23)$ & $284(26)$ \\
\hline Decreased susceptibility $(0.064<\mathrm{MIC} \leq 1 \mathrm{mg} / \mathrm{L})$ & $2,741(59)$ & $863(62)$ & $373(66)$ & $661(60)$ \\
\hline $\begin{array}{l}\text { Low-level chromosomal resistance }(\mathrm{MIC}>1 \mathrm{mg} / \mathrm{L} \text { and beta- } \\
\text { lactamase negative) }\end{array}$ & $161(3)$ & $46(3)$ & $11(2)$ & $52(5)$ \\
\hline $\begin{array}{l}\text { High-level plasmid-mediated resistance (beta-lactamase } \\
\text { positive) }\end{array}$ & $477(10)$ & $108(8)$ & $52(9)$ & $96(9)$ \\
\hline Total number of strains tested $(\mathrm{N}=7,689$ strains $)$ & $4,630(100)$ & $1,400(100)$ & $566(100)$ & $1,093(100)$ \\
\hline \multicolumn{5}{|l|}{ Tetracycline } \\
\hline Susceptible strains $(\mathrm{MIC} \leq 0.5 \mathrm{mg} / \mathrm{L})$ & $1,000(22)$ & $328(23)$ & $104(18)$ & $188(17)$ \\
\hline Decreased susceptibility $(0.5<\mathrm{MIC} \leq 1 \mathrm{mg} / \mathrm{L})$ & $1,516(33)$ & $406(29)$ & $157(28)$ & $294(27)$ \\
\hline Low-level chromosomal resistance $(1<\mathrm{MIC} \ll 16 \mathrm{mg} / \mathrm{L})$ & $1,445(31)$ & $449(32)$ & $171(30)$ & $366(33)$ \\
\hline High-level plasmid-mediated resistance $(\mathrm{MIC} \geq 16 \mathrm{mg} / \mathrm{L})$ & $670(14)$ & $217(16)$ & $132(23)$ & $245(22)$ \\
\hline Total number of strains tested $(\mathrm{N}=7,688$ strains $)$ & $4,631(100)$ & $1,400(100)$ & $564(100)$ & $1,093(100)$ \\
\hline \multicolumn{5}{|l|}{ Ciprofloxacin } \\
\hline Susceptible strains (MIC $\leq 0.064 \mathrm{mg} / \mathrm{L})$ & $2,831(61)$ & $814(58)$ & $861(57)$ & $664(61)$ \\
\hline Decreased susceptibility $(0.032<\mathrm{MIC} \leq 0.064 \mathrm{mg} / \mathrm{L})$ & $19((1)$ & $2(\ll 1)$ & $7(\ll 1)$ & $1(\ll 1)$ \\
\hline Low-level resistance $(0.064<\mathrm{MIC}<1 \mathrm{mg} / \mathrm{L})$ & $200(4)$ & $53(4)$ & $117(8)$ & $19(2)$ \\
\hline High-level resistance $(\mathrm{MIC} \geq 1 \mathrm{mg} / \mathrm{L})$ & $1,584(34)$ & $531(38)$ & $536(35)$ & $409(37)$ \\
\hline Total number of strains tested ( $\mathrm{N}=8,648$ strains) & $4,634(100)$ & $1,400(100)$ & $1,521(100)$ & $1,093(100)$ \\
\hline \multicolumn{5}{|l|}{ Spectinomycin ${ }^{c}$} \\
\hline Susceptible strains $(\mathrm{MIC} \leq 64 \mathrm{mg} / \mathrm{L})$ & $4,631(100)$ & $1,400(100)$ & $1,426(100)$ & $1,093(100)$ \\
\hline Total number of strains tested $(\mathrm{N}=8,550$ strains) & $4,631(100)$ & $1,400(100)$ & $1,426(100)$ & $1,093(100)$ \\
\hline \multicolumn{5}{|l|}{ Cefixime $^{d}$} \\
\hline Susceptible strains $(\mathrm{MIC} \leq 0.125 \mathrm{mg} / \mathrm{L})$ & $1,983(100)$ & 1,391 (99) & $1,511(99)$ & $1,060(97)$ \\
\hline Decreased susceptibility (MIC>0.125mg/L) & $8((1)$ & $8(1)$ & $10(1)$ & $33(3)$ \\
\hline Total number of strains tested ( $\mathrm{N}=6,004$ strains) & $1,991(100)$ & $1,399(100)$ & $1,521(100)$ & $1,093(100)$ \\
\hline \multicolumn{5}{|l|}{ Ceftriaxone } \\
\hline Susceptible strains $(\mathrm{MIC} \leq 0.125 \mathrm{mg} / \mathrm{L})$ & $4,631(100)$ & $1,398(100)$ & $1,521(100)$ & $1,093(100)$ \\
\hline Decreased susceptibility (MIC>0.125mg/L) & $\mathrm{o}(\mathrm{o})$ & $2(\ll 1)$ & $\mathrm{o}(0)$ & $\mathrm{o}(\mathrm{o})$ \\
\hline Total number of strains tested $(\mathrm{N}=8,645$ strains) & $4,631(100)$ & $1,400(100)$ & $1,521(100)$ & $1,093(100)$ \\
\hline \multicolumn{5}{|l|}{ Multidrug resistance $\mathrm{e}^{\mathrm{e}}$} \\
\hline No multidrug resistance & $1,989(100)$ & $1,396(100)$ & $563(100)$ & $1,075(98)$ \\
\hline Multidrug resistant strains & $1(\ll 1)$ & $3(<1)$ & $1(\ll 1)$ & $18(2)$ \\
\hline Total number of strains tested ( $\mathrm{N}=5,046$ strains) & $1,990(100)$ & $1,399(100)$ & $564(100)$ & $1,093(100)$ \\
\hline
\end{tabular}

EUCAST: European Committee on Antimicrobial Susceptibility Testing; MIC: minimum inhibitory concentration.

EUCAST 2013 criteria were used for the definition of resistance [13].

a Rénago is the national gonorrhoea network, a sentinel network based on voluntarily participating public and private laboratories.

b In 2011 , only $37 \%$ of strains were tested for penicillin $\mathrm{G}$ and tetracycline because of budgetary constraints.

For spectinomycin, precise analysis of MIC values was restricted to the period when the new E-test was used (from May 2011).

Cefixime was tested from 2008 onwards. There is no official threshold defining gonococcal resistance to third generation cephalosporins but $0.125 \mathrm{mg} / \mathrm{L}$ is used in practice [25].

Defined as resistance to penicillin G (MIC>1mg/L or beta-lactamase positive), tetracycline (MIC>1mg/L), and ciprofloxacin (MIC >0.064mg/L) and demonstration of elevated MICs of cefixime or ceftriaxone (MIC>0.125mg/L) [25].

\section{Evolution of the susceptibility of gonococcal strains to antibiotics}

The analysis is based on 8,649 gonococcal strains tested by the NLR. Proportionally, more strains were tested from men (70\%: 7,569/10,815) than women (42\%: 1,070/2,564; p<0.001). Furthermore anal samples were tested proportionally more often (84\%: $730 / 868)$ than samples from the other anatomical sites (63\%: 7,898/12,478; p<0.001).

The majority of strains $(73 \%: 5,641 / 7,689)$ presented decreased susceptibility to penicillin G (MIC>0.064 $\mathrm{mg} / \mathrm{L})$. The proportion of strains resistant to penicillin $\mathrm{G}(\mathrm{MIC}>1 \mathrm{mg} / \mathrm{L})$ fluctuated between $10(12 / 126$ in 2002) and $21 \%(109 / 512$ in 2005 ; Figure $3,13 \%$ on average: $1,003 / 7,689)$ during the study period, with, in 2012 , $14 \%$ of strains resistant (148/1,093; 95\% confidence interval (Cl): 11.6-15.7). Nearly three quarters of resistant strains $(733 / 1,003)$ had a high level of plasmidmediated penicillin resistance (Table 2 ).

The proportion of strains resistant to tetracycline increased from $29 \%(43 / 150)$ in 2001 to $56 \%(611 / 1,093)$ in 2012 (Figure 3). In 2012, 33\% (366/1,093) of the 
strains (95\% Cl: 31-36) had low-level chromosomal resistance and 22\% (245/1,093; 95\% Cl: 20-25) had high-level plasmid-mediated resistance.

The proportion of strains resistant to ciprofloxacin (MIC>0.06 mg/L) increased sharply between 2003 (15\%: $30 / 195$, $13 \%$ : 25/195 of which with high-level resistance (MIC $\geq 1 \mathrm{mg} / \mathrm{L})$ and 2006 (47\%: 243/514, 43\%: $221 / 514$ of which with high-level resistance). It then remained quite high at around $42 \%$ (Figure 3). In 2012, $2 \%(19 / 1,093 ; 95 \% \mathrm{Cl}: 1.0-2.7)$ of the strains had lowlevel resistance while $37 \%(409 / 1,093 ; 95 \% \mathrm{Cl}: 35-40)$ had high-level resistance.

No strain resistant to spectinomycin was detected throughout the whole study period. The change in E-test type from May 2011 means that a comparison of the evolution of the distribution of MIC values before and after this date could not be made for this antibiotic. Nevertheless, the median MIC between 2001 (6 $\mathrm{mg} / \mathrm{L})$ and 2011 until April $(8 \mathrm{mg} / \mathrm{L})$ remained relatively stable. Similarly, the median MIC remained stable between 2011 after May (16 mg/L) and 2012 (16 mg/L).

The proportion of strains with decreased susceptibility to cefixime (MIC>0.125 mg/L) was less than $1 \%$ until 2011 (Table 2). In 2011 it was 0.7\% (10/1,521; 95\% Cl: $0.3-1.2)$ and increased significantly to $3.0 \%$ in 2012 (33/1,093; 95\% Cl: 2.1-4.2; p<0.001). The proportion of strains with MIC values>0.094 $\mathrm{mg} / \mathrm{L}$ increased consistently between 2008 and 2012 (Figure 4).

In 2010 , for the first time two strains of 1,400 (0.14\%; $95 \% \mathrm{Cl}: 0.02-0.57)$ showed decreased susceptibility to

\section{FIGURE 4}

Evolution of the distribution of minimum inhibitory concentration values for cefixime, Rénago ${ }^{a}$ network, 2008-2012

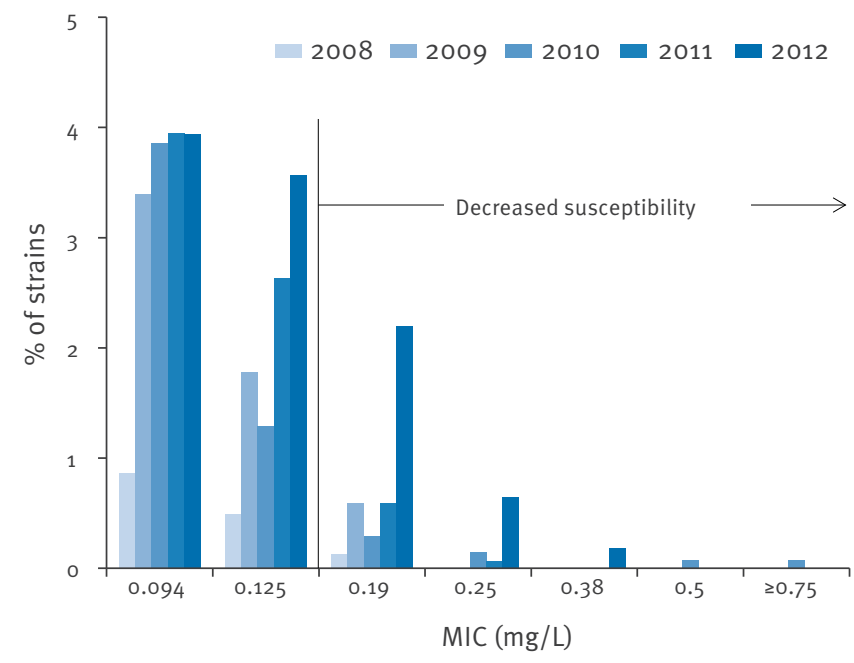

MIC: minimum inhibitory concentration.

a Rénago is the national gonorrhoea network, a sentinel network based on voluntarily participating public and private laboratories.

\section{FIGURE 5}

Evolution of the distribution of minimum inhibitory concentration values for ceftriaxone, Rénago ${ }^{a}$ network, 2008-2012

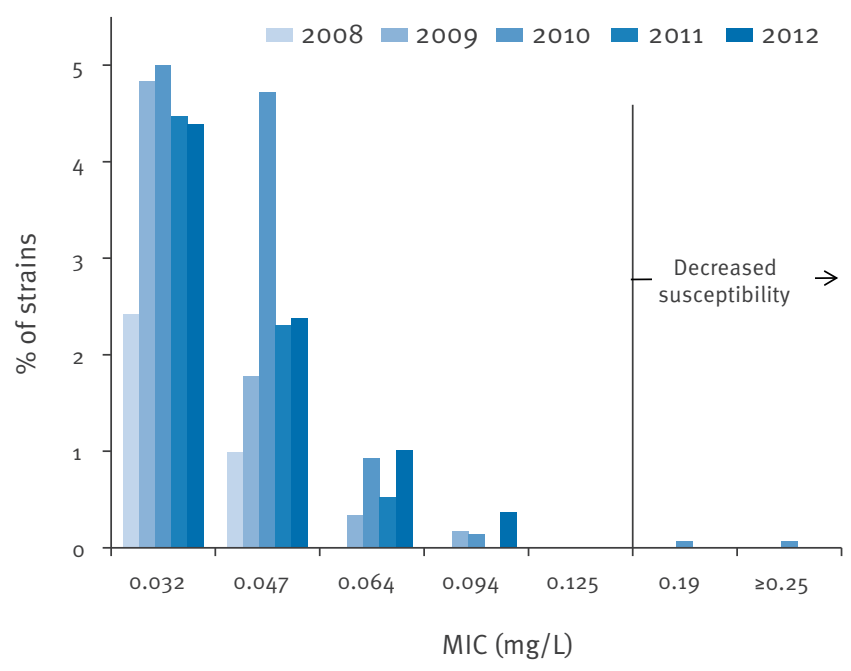

MIC: minimum inhibitory concentration.

a Rénago is the national gonorrhoea network, a sentinel network based on voluntarily participating public and private laboratories.

ceftriaxone, and both of these also showed decreased susceptibility to cefixime. Both cases were in men. One was about twenty years of age (MIC of $0.19 \mathrm{mg} / \mathrm{L}$ for ceftriaxone and $0.5 \mathrm{mg} / \mathrm{L}$ for cefixime). The other was a MSM in his fifties (MIC of $0.75 \mathrm{mg} / \mathrm{L}$ for ceftriaxone and $2 \mathrm{mg} / \mathrm{L}$ for cefixime) [14]. No decreased susceptibility to ceftriaxone was subsequently found in 2011 or in 2012. The upward trend in MIC values between 2008 and 2010 was not observed in the 2011 to 2012 period (Figure 5).

Finally, multidrug resistant strains were rare over the 2001 to 2011 period (5/3,953: $0.1 \%$; 95\% Cl: $0-0.3$ ) but their proportion increased significantly in 2012 (18/1,093: 1.6\%; 95\% Cl: 1.0-2.6; p<0.001).

Restricted analysis of those laboratories which reported throughout the whole study period and continued to participate in microbiological surveillance during 2012 provided similar results in terms of the evolution of the susceptibility of gonococcal strains to antibiotics between 2001 and 2012 (data not shown).

Factors associated with a reduction in the susceptibility of gonococcal strains to third generation cephalosporins in patients 15 years and older

Univariate analysis was performed using the variables from Table 1. The proportion of strains with decreased susceptibility to cefixime (MIC $\geq 0.094 \mathrm{mg} / \mathrm{L})$ and to ceftriaxone ( $\mathrm{MIC} \geq 0.032 \mathrm{mg} / \mathrm{L}$ ) (Table 3 ) was significantly associated with age group, year of surveillance and 
TABLE 3

Factors associated with decreased susceptibility of gonococcal strains to third generation cephalosporins in patients 15 years-old and over, Rénago network ${ }^{\mathrm{a}}$, 2001-2012

\begin{tabular}{|c|c|c|c|c|c|c|}
\hline \multirow[t]{2}{*}{ Variables } & \multicolumn{3}{|c|}{$\begin{array}{c}\text { Cefixime }^{\mathrm{b}} \\
\text { MIC } \geq 0.094 \mathrm{mg} / \mathrm{L}\end{array}$} & \multicolumn{3}{|c|}{$\begin{array}{c}\text { Ceftriaxone } \\
M I C \geq 0.032 \mathrm{mg} / \mathrm{L}\end{array}$} \\
\hline & $\mathrm{n} / \mathrm{N}(\%)$ & ORa $(95 \% \mathrm{Cl})$ & $\mathrm{p}$ & $\mathrm{n} / \mathrm{N}(\%)$ & ORa $(95 \% \mathrm{Cl})$ & $\mathrm{p}$ \\
\hline \multicolumn{7}{|l|}{ Years } \\
\hline $2001-2009$ & $80 / 1,988(4)$ & Ref. & - & $201 / 4,622(4)$ & Ref. & - \\
\hline 2010 & $79 / 1,394(6)$ & $1.43(1.03-1.99)$ & 0.034 & $152 / 1,395(11)$ & $2.52(2.00-3.18)$ & $<0.001$ \\
\hline 2011 & $110 / 1,520(7)$ & $1.78(1.31-2.43)$ & $<0.001$ & $111 / 1,520(7)$ & $1.54(1.19-1.98)$ & 0.001 \\
\hline 2012 & $115 / 1,090(11)$ & $2.65(1.94-3.62)$ & $<0.001$ & $89 / 1,090(8)$ & $1.66(1.26-2.19)$ & $<0.001$ \\
\hline \multicolumn{7}{|l|}{ Sex } \\
\hline Men & $332 / 5,217(6)$ & Ref. & - & $485 / 7,556(6)$ & Ref. & - \\
\hline Women & $52 / 768(7)$ & $1.73(0.69-4.35)$ & 0.24 & $67 / 1,061(6)$ & $1.49(0.66-3.35)$ & 0.34 \\
\hline \multicolumn{7}{|l|}{ Age group in years } \\
\hline $15-24$ & $98 / 2,048(5)$ & Ref. & - & $147 / 2,717(5)$ & Ref. & - \\
\hline $25-34$ & $140 / 2,113(7)$ & $1.41(1.08-1.86)$ & 0.013 & $203 / 3,103(7)$ & $1.28(1.02-1.60)$ & 0.036 \\
\hline $35-44$ & $79 / 1,048(8)$ & $1.78(1.30-2.45)$ & $<0.001$ & $120 / 1,629(7)$ & $1.55(1.19-2.01$ & 0.001 \\
\hline$\geq 45$ & $60 / 659(9)$ & $1.97(1.39-2.78)$ & $<0.001$ & $72 / 951(8)$ & $1.49(1.10-2.02)$ & 0.010 \\
\hline \multicolumn{7}{|l|}{ Anatomical site } \\
\hline Urethra or urine & $309 / 4,784(6)$ & Ref. & - & $435 / 6,763(6)$ & Ref. & - \\
\hline Cervix or vagina & $45 / 690(7)$ & $0.56(0.21-1.47)$ & 0.24 & $58 / 949(6)$ & $0.69(0.29-1.61)$ & 0.39 \\
\hline Anus & $19 / 392(5)$ & $0.88(0.51-1.52)$ & 0.65 & $43 / 729(6)$ & $1.19(0.81-1.73)$ & 0.37 \\
\hline Pharynx & $7 / 35(20)$ & $4.21(1.62-10.91)$ & 0.003 & $7 / 52(13)$ & $2.86(1.17-6.99)$ & 0.021 \\
\hline Other sites & $4 / 78(5)$ & $0.71(0.22-2.28)$ & 0.56 & $8 / 113(7)$ & $0.96(0.41-2.26)$ & 0.93 \\
\hline \multicolumn{7}{|l|}{ Place of consultation } \\
\hline Private sector or clinic & $286 / 3,994(7)$ & Ref. & - & $382 / 5,365(7)$ & Ref. & - \\
\hline Hospital & $39 / 883(4)$ & $0.55(0.30-1.00)$ & 0.052 & $89 / 1,459(6)$ & $1.13(0.71-1.79)$ & 0.60 \\
\hline Specialised facilities for STIS ${ }^{d}$ & $51 / 983(5)$ & $0.77(0.48-1.23)$ & 0.28 & $68 / 1,276(5)$ & $0.86(0.60-1.25)$ & 0.44 \\
\hline Other structures & $4 / 36(11)$ & $1.07(0.32-3.58)$ & 0.92 & $3 / 36(8)$ & $0.67(0.16-2.85)$ & 0.59 \\
\hline \multicolumn{7}{|l|}{ Prescribing doctor } \\
\hline General practitioner & $276 / 4,198(7)$ & Ref. & - & $379 / 5,634(7)$ & Ref. & - \\
\hline Gynaecologist & $28 / 363(8)$ & $1.18(0.68-2.07)$ & 0.55 & $35 / 587(6)$ & $1.38(0.90-2.11)$ & 0.14 \\
\hline Dematologist-venereologist & $20 / 358(6)$ & $1.43(0.83-2.47)$ & 0.20 & $37 / 760(5)$ & $0.98(0.61-1.57)$ & 0.93 \\
\hline Other medical specialisations & $50 / 903(6)$ & $1.19(0.76-1.84)$ & 0.45 & $85 / 1,288(7)$ & $1.13(0.79-1.61)$ & 0.51 \\
\hline \multicolumn{7}{|l|}{ Type of laboratory } \\
\hline Private & $308 / 4,501(7)$ & Ref. & - & $428 / 6,349(7)$ & Ref. & - \\
\hline Hospital & $63 / 1,251(5)$ & $1.19(0.71-1.94)$ & 0.52 & $107 / 1,966(5)$ & $0.72(0.48-1.08)$ & 0.12 \\
\hline Community clinic & $13 / 240(5)$ & $1.24(0.60-2.56)$ & 0.56 & $18 / 312(6)$ & $0.98(0.52-1.83)$ & 0.94 \\
\hline \multicolumn{7}{|l|}{ Laboratory location (area) } \\
\hline Paris region & $96 / 2,073(5)$ & Ref. & - & $170 / 3,379(5)$ & Ref. & - \\
\hline North-west & $86 / 1,324(6)$ & $1.36(0.98-1.90)$ & 0.07 & $111 / 1,747(6)$ & $1.27(0.97-1.67)$ & 0.09 \\
\hline North-east & $107 / 1,095(10)$ & $1.99(1.45-2.73)$ & $<0.001$ & $154 / 1,451(11)$ & $2.23(1.73-2.87)$ & $<0.001$ \\
\hline South-east & $54 / 881(6)$ & $1.06(0.72-1.56)$ & 0.76 & $70 / 1,226(6)$ & $1.08(0.78-1.49)$ & 0.65 \\
\hline South-west & $41 / 619(7)$ & $1.23(0.81-1.85)$ & 0.33 & $48 / 824(6)$ & $1.11(0.78-1.60)$ & 0.56 \\
\hline
\end{tabular}

MIC: minimum inhibitory concentration; ORa: odds ratio adjusted for the other variables in the table; $95 \% \mathrm{Cl}$ : $95 \%$ confidence interval; ref.: reference group; STIs: sexually transmitted infections.

For each variable, the number of strains with decreased susceptibility $(\mathrm{n})$ is given relative to the total tested for the antibiotic (N) as well as the percentage. The multivariate analysis includes all the variables in the Table. Significant results (p<0.05) are in bold.

a Rénago is the national gonorrhoea network, a sentinel network based on voluntarily participating public and private laboratories.

b Cefixime tested from 2008 onwards; MIC $\geq 0.094 \mathrm{mg} / \mathrm{L}$ for 385 strains of 6,004 (6.4\%).

Ceftriaxone: $M I C \geq 0.032 \mathrm{mg} / \mathrm{L}$ for 554 strains of $8,645(6.4 \%)$.

d Specialised facilities for the management of STI: STI clinics, free anonymous counselling and testing services and family planning centres. 
geographical area. This proportion was also greater in the absence of gonorrhoea-associated STI, notably in the absence of co-infection with chlamydia. Furthermore the proportion of strains with decreased susceptibility to cefixime was associated with anatomical site of sample, presence of symptoms and place of consultation.

Multivariate analysis (Table 3) was performed using the variables from Table 1 excluding four variables with a large proportion of missing data (as mentioned in the methods section). The proportion of strains with decreased susceptibility to cefixime (MIC $\geq 0.094 \mathrm{mg} / \mathrm{L}$ ) increased in the 2010 to 2012 period. Indeed, this proportion was 2.7 times greater in 2012 than for the period between 2001 and 2009. This reduced susceptibility increased with the patients' age. It was almost four times higher for strains derived from the pharynx than for those derived from the urethra, even when analysis was restricted to male patients (adjusted odds ratio $4.2 ; 95 \% \mathrm{Cl}: 1.5-11.6 ; \mathrm{p}=0.006)$. Finally, the decrease in susceptibility to cefixime was found to be higher in the north-eastern area of France.

The proportion of strains with decreased susceptibility to ceftriaxone increased in the 2010 to 2012 period, this increase being particularly sharp in 2010. Taking 2010 as the reference year, the proportion of strains with decreased susceptibility to ceftriaxone $(\mathrm{MIC} \geq 0.032$ $\mathrm{mg} / \mathrm{L}$ ) significantly diminished in the 2011 to 2012 period. As was the case for cefixime, decreased susceptibility for ceftriaxone increased with patients' age, was higher for pharyngeal-based strains (even when restricting the analysis to male patients) (adjusted odds ratio: $3.4 ; 95 \% \mathrm{Cl}: 1.4-8.2 ; \mathrm{p}=0.008$ ) and was higher in the north-eastern area of France.

Multivariate analysis of the 2001 to 2012 period, restricted to the laboratories which continued microbiological surveillance in 2012, provided similar results (data not shown).

\section{Discussion}

The microbiological surveillance network in France shows that the proportion of resistant strains to antibiotics fluctuated around $13 \%$ for penicillin $\mathrm{G}$ over the whole study period. It increased throughout the study for tetracycline, reaching $56 \%$ in 2012 . For ciprofloxacin it increased between 2003 and 2006 after which it remained high at around $42 \%$. These three families of antibiotics have a resistance level which prevents them from being used in current practice for the treatment of gonorrhoea. Indeed, according to the World Health Organization, first-line treatment must cure at least $95 \%$ of patients and must not be used if more than $5 \%$ of strains are resistant [2].

Gonorrhoea was susceptible to spectinomycin throughout the study period. The marketing of this antibiotic in France stopped in 2008 and then started again since 2011. However, therapeutic failures for pharyngeal-based infections have led it to become a second-line treatment when there are contraindications to beta-lactam antibiotics [15].

The proportion of strains with decreased susceptibility to cefixime (MIC>0.125 $\mathrm{mg} / \mathrm{L}$ ) remained moderate, less than 5\%, but it quadrupled between 2011 and 2012. Furthermore, the proportion of isolates with high MIC values (MIC $\geq 0.094 \mathrm{mg} / \mathrm{L})$ increased consistently in recent years (Figure 4 and Table 3 ). The only two strains presenting MICs>0.125 mg/L to ceftriaxone were both detected in France in 2010, and one of these was associated with therapeutic failure using cefixime in an infected patient [14]. With respect to ceftriaxone, the number or proportion of isolates with high MIC values (MIC $\geq 0.032 \mathrm{mg} / \mathrm{L})$ did not increase in 2011 or 2012. The very rare cases of decreased susceptibility to ceftriaxone [14,16-19] and cases of therapeutic failure with cefixime described in Japan, Canada and Europe $[14,20-23]$, confirm the recommendations made by the French Agency for Medicine published in 2005 [12], which were reaffirmed in 2008 [15]. These guidelines recommend the use of ceftriaxone $(500 \mathrm{mg}$ singledose injection) in first-line treatment, and that the use of cefixime (400 $\mathrm{mg}$ single-dose oral) be reserved for cases of patient refusal or when parenteral treatment is not possible.

Nevertheless, the increase in gonococcal decreased susceptibility to cefixime observed in France suggests that clinicians may have continued to prescribe this antibiotic as a first-line treatment after the recommendations of 2005 were published (and reaffirmed in 2008). Indeed, a study performed in 2008 on general practitioners in the 'Sentinelles' network showed that only a minority of prescribing doctors were aware of the 2005 recommendation to abandon ciprofloxacin in favour of TGC [24]. By analogy, it is possible that in 2012 doctors had not yet sufficiently implemented the recommendation reiterated in 2008 regarding the use of TGCs [15]. A new study on doctors' prescriptions could help support this hypothesis. Another hypothesis to explain the recent increase in gonococcal resistance to cefixime is the spread of a resistant clone [25].

The levels of resistance to penicillin G, tetracycline and ciprofloxacin in France were higher than those found in the United States, but of the same order for TGC and multidrug resistance [26]. In contrast, the levels of resistance in France were of the same order as European levels for penicillin $\mathrm{G}$ and ciprofloxacin, but lower for TGC [27].

We currently do not have data on the susceptibility of gonorrhoea to azithromycin. In France this antibiotic is taken in a single, $1 \mathrm{~g}$ dose with ceftriaxone in suspected cases of urethritis and cervicitis [12,15]. Elsewhere, notably in the United States, azithromycin is recommended in monotherapy for gonococcal infections, in the case of allergies to TGC [28]. Because of resistance to azithromycin described in various countries $[26,29]$ 
this antibiotic is being tested within the Rénago network as of 2013.

Our study shows factors associated with a reduction in the susceptibility to TGC. We acknowledge that the combination of data from 2001 to 2009 only allowed to highlight the recent epidemiological and microbiological changes. The proportion of strains with decreased susceptibility to TGC increased with patients' age. This has already been observed for other antibiotics (penicillin and tetracycline) in Canada [29]. A lower proportion of gonococcal resistant strains in the case of co-infection with chlamydia was found for cefixime in the United Kingdom [30] and for ciprofloxacin at the European level [27], although the reason for this is not clearly established.

The proportion of strains with decreased susceptibility to TGC did not differ significantly according to sex. Anal-based strains did not present higher decreases in susceptibility than urethral-based strains. However, the proportion of pharyngeal-based strains with decreased susceptibility to TGC was three to four times higher than urethral-based strains. This may be explained by the horizontal transfer of gene mutations associated with decreased susceptibility to TGC from oral commensal Neisseria [31]. Anal and pharyngeal gonorrhoea in men was probably acquired through homosexual transmission, although the absence of information on sexual behaviours from the Rénago network prevents us from being certain about this. Several studies have shown that MSM are likely to be infected more frequently and more quickly than heterosexuals by resistant gonococcal strains $[26,30,32]$. This fact highlights the need for specific surveillance of antibiotic susceptibility in MSM. We found that the monitoring of anal strains brought information on resistance similar to those of urethral strains. Despite the absence of behavioural data, our study shows, however, that increased monitoring of pharyngealbased strains with respect to decreased susceptibility to TGC seems essential.

Finally, we observed a higher level of decreased susceptibility in the north-eastern area of France. It is hard to interpret the reason for this. Obviously this area should remain under close scrutiny, while still keeping the national distribution of the network's laboratories homogeneous.

In the Rénago network, an increase in the number of declared gonococcal infections occurred over the 2001 to 2012 period. Several interlinked phenomena contributed to this: the real growth in infections, the increase in NAAT diagnoses, the increase in the number of participating laboratories and the growing shift towards the consolidation of laboratories. Despite this complex evolution, the Rénago network continued to help monitor gonococcal resistance to antibiotics. This microbiological surveillance network would appear to be reliable as the changes that have been made to it have (the reduction by half of the number of laboratories submitting strains to the NRL), a priori, had little or no effect on the proportion of resistant strains observed. Restricted analysis to those laboratories which continued to participate in microbiological surveillance in 2012 provides strong evidence for this.

The surveillance of gonococcal resistance by the Rénago network brings with it several limitations. Overseas French regions are not yet included in surveillance. Furthermore, the laboratories participating in the network do not provide a representative sample of metropolitan France. Extrapolation of the results therefore requires supplementary investigations. An assessment of the completeness of this laboratory surveillance system is ongoing but results are not yet available. Finally, this network does not collect behavioural data as microbiologists do not often have access to such information. This explains the large amount of missing values for certain variables. One way for us to have behavioural data, in particular sexual orientation, is to monitor the susceptibility of gonococcal strains in patients diagnosed through our second voluntary network, the RésIST network of clinicians.

The emergence of resistance to TGC is extremely worrying as the latter represent the last line of treatment, with no therapeutic alternatives currently available [31]. This fact justifies the continuation of microbiological surveillance of gonorrhoea at a collective level in order to adjust therapeutic recommendations. Meanwhile, surveillance of therapeutic failure with respect to $\mathrm{TGC}$ is currently being implemented at the European level [33]. Given the increase in NAAT diagnosis, it is essential that medical laboratories continue to perform gonococcal cultures which adapt care to the individual's needs while waiting for molecular tests on susceptibility to antibiotics to be developed and made accessible [2].

\section{Acknowledgements}

GLR conceived and wrote the paper. AG, BB, EC, CS and PS participated in the design of the analysis, commented on the first draft of the paper and approved the final version.

\section{Conflict of interest}

None declared.

Authors' contributions

We thank Betty Basselier for the Rénago network management and for data entry. We thank Jude Sweeney for the English revision and editing of the manuscript.

\section{References}

1. Bignell C, Unemo M. 2012 European guideline on the diagnosis and treatment of gonorrhoea in adults. November 2012. International Union against Sexually Transmitted Infections 
(IUSTI) Europe. [Accessed 21 Aug 2014]. Available from: http:// www.iusti.org/regions/europe/pdf/2012/Gonorrhoea_2012.pdf

2. Tapsall JW. Antibiotic resistance in Neisseria gonorrhoeae. Clin Infect Dis. 2005;41(Suppl 4):S263-8.

http://dx.doi.org/10.1086/430787

3. Hook EW, Handsfield HH. Gonococcal infections in the adult. In: Holmes KK, Sparling PF, Stamm WE, et al. eds. Sexually Transmitted Diseases, 4th edition. New York: McGraw Hill, Inc.; 2008: 627-645.

4. Van der Heyden JH, Catchpole MA, Paget WJ, Stroobant A. Trends in gonorrhoea in nine western European countries, 1991-6. European Study Group. Sex Transm Infect. 2000;76(2):110-6. http://dx.doi.org/10.1136/sti.76.2.110

5. Herida M, Sednaoui P, Goulet V. Gonorrhoea surveillance system in France: 1986-2000. Sex Transm Dis. 2004;31(4):20914 .

http://dx.doi.org/10.1097/01.OLQ.0000118426.66742.9E

6. Nicoll A, Hamers FF. Are trends in HIV, gonorrhoea, and syphilis worsening in western Europe? BMJ. 2002;324(7349):1324-7. http://dx.doi.org/10.1136/bmj.324.7349.1324

7. Centers for Disease Control and Prevention. Resurgent bacterial sexually transmitted disease among men who have sex with men-King County, Washington, 1997-1999. MMWR Morb Mortal Wkly Rep. 1999;48(35):773-7.

8. La Ruche G, Goulet V, Bouyssou A, Sednaoui P, De Barbeyrac $B$, Dupin N, et al. Épidémiologie actuelle des infections sexuellement transmissibles bactériennes en France. [Current epidemiology of bacterial STIs in France]. Presse Med. 2013;42(4 Pt 1):432-9. French. http://dx.doi.org/10.1016/j.Ipm.2012.09.022

9. Nguyen E, Bouyssou A, Lassau F, Basselier B, Sednaoui P, Anne Gallay A et al. Progression importante des infections à gonocoques en France: données des réseaux Rénago et RésIST au 31 décembre 2009. [Significant increase of Neisseria gonorrhoeae infections in France: data from the RENAGO and RESIST networks as of 31 December 2009]. Bull Epidemiol Hebd. 2011;(26-28):301-4. French.

10. Herida M, Desenclos JC, Martin IM, Goulet V, Laurent E, Sednaoui P. Increase of Neisseria gonorrhoeae ciprofloxacin resistance in France in 2001-2003. Sex Transm Dis. 2006;33(1):6-7. http://dx.doi.org/10.1097/01.olq.0000187197.85419.f8

11. Unemo M, Shafer WM. Antibiotic resistance in Neisseria gonorrhoeae: origin, evolution, and lessons learned for the future. Ann N Y Acad Sci. 2011;1230:E19-28. http://dx.doi.org/10.1111/j.1749-6632.2011.06215.x

12. Agence française de sécurité sanitaire des produits de santé. Traitement antibiotique des urétrites et cervicites non compliquées. [Antibiotic treatment of uncomplicated urethritis and cervicitis]. Med Mal Infect. 2006;36(1):27-35. French. http://dx.doi.org/10.1016/j.medmal.2005.10.009

13. European Committee on Antimicrobial Susceptibility Testing (EUCAST). Breakpoint tables for interpretation of MICS and zone diameters. Version 3.1, 2013. Växjö: EUCAST; 2013. [Accessed 21 Aug 2014]. Available from: http://www. eucast.org/fileadmin/src/media/PDFs/EUCAST_files/ Breakpoint_tables/Breakpoint_table_v_3.1.pdf

14. Unemo M, Golparian D, Nicholas R, Ohnishi M, Gallay A Sednaoui P. High-level cefixime- and ceftriaxone-resistant Neisseria gonorrhoeae in France: novel penA mosaic allele in a successful international clone causes treatment failure. Antimicrob Agents Chemother. 2012;56(3):1273-80. http://dx.doi.org/10.1128/AAC.05760-11

15. Agence française de sécurité sanitaire des produits de santé. Traitement antibiotique probabiliste des urétrites et cervicites non compliquées. Actualisation octobre 2008. [Probabilistic antibiotic treatment of uncomplicated urethritis and cervicitis. October 2008 update]. Saint-Denis,: Afssaps; 2008. [Accessed 21 Aug 2014]. Available from: http://www.webcitation. org/6DQ998X4G

16. Ohnishi M, Saika T, Hoshina S, Iwasaku K, Nakayama $\mathrm{S}$, Watanabe $\mathrm{H}$, et al. Ceftriaxone-resistant Neisseria gonorrhoeae, Japan. Emerg Infect Dis. 2011;17(1):148-9. http://dx.doi.org/10.3201/eid1701.100397

17. Y Chen M, Stevens K, Tideman R, Zaia A, Tomita T, Fairley CK, et al. Failure of $500 \mathrm{mg}$ of ceftriaxone to eradicate pharyngeal gonorrhoea, Australia. J Antimicrob Chemother. 2013;68(6):1445-7. http://dx.doi.org/10.1093/jac/dkto17

18. Tapsall J, Read P, Carmody C, Bourne C, Ray S, Limnios A, et al. Two cases of failed ceftriaxone treatment in pharyngeal gonorrhoea verified by molecular microbiological methods. I Med Microbiol. 2009;58(Pt 5):683-7. http://dx.doi.org/10.1099/jmm.0.007641-0
19. Cámara J, Serra J, Ayats J, Bastida T, Carnicer-Pont D, Andreu A, et al. Molecular characterization of two high-level ceftriaxoneresistant Neisseria gonorrhoeae isolates detected in Catalonia, Spain. J Antimicrob Chemother. 2012;67(8):1858-60. http://dx.doi.org/10.1093/jac/dks162

20. Yokoi S, Deguchi T, Ozawa T, Yasuda M, Ito S, Kubota Y, et al. Threat to cefixime treatment for gonorrhea. Emerg Infect Dis. 2007;13(8):1275-7.

21. Allen VG, Mitterni L, Seah C, Rebbapragada A, Martin $I E$, Lee $C$, et al. Neisseria gonorrhoeae treatment failure and susceptibility to cefixime in Toronto, Canada. JAMA. 2013;309(2):163-70.

http://dx.doi.org/10.1001/jama.2012.176575

22. Unemo M, Golparian D, Syversen G, Vestrheim DF, Moi H. Two cases of verified clinical failures using internationally recommended first-line cefixime for gonorrhoea treatment, Norway, 2010. Euro Surveill. 2010;15(47). pii: 19721.

23. Unemo M, Golparian D, Stary A, Eigentler A. First Neisseria gonorrhoeae strain with resistance to cefixime causing gonorrhoea treatment failure in Austria, 2011. Euro Surveill. 2011;16(43). pii: 19998.

24. Falchi A, Lasserre A, Gallay A, Blanchon T, Sednaoui P, Lassau $\mathrm{F}$, et al. A survey of primary care physician practices in antibiotic prescribing for the treatment of uncomplicated male gonococcal urethritis. BMC Fam Pract. 2011;12:35. http://dx.doi.org/10.1186/1471-2296-12-35

25. Chisholm SA, Unemo M, Quaye N, Johansson E, Cole MJ, Ison CA, et al. Molecular epidemiological typing within the European Gonococcal Antimicrobial Resistance Surveillance Programme reveals predominance of a multidrug-resistant clone. Euro Surveill. 2013;18(3). pii: 20358.

26. Kirkcaldy RD, Zaidi A, Hook EW 3rd, Holmes KH, Soge O, del Rio C, et al. Neisseria gonorrhoeae antimicrobial resistance among men who have sex with men and men who have sex exclusively with women: the Gonococcal Isolate Surveillance Project, 2005-2010. Ann Intern Med. 2013;158(5 Pt 1):321-8. http://dx.doi.org/10.7326/0003-4819-158-5-201303050-00004

27. European Centre for Disease Prevention and Control (ECDC). Gonococcal antimicrobial susceptibility surveillance in Europe, 2011. Stockholm: ECDC; 2013. [Accessed 21 Aug 2014]. Available from: http://www.ecdc.europa.eu/en/publications/ publications/gonococcal-antimicrobial-susceptibilitysurveillance-27-mar-2013.pdf

28. Centers for Disease Control and Prevention (CDC). CDC Grand Rounds: the growing threat of multidrug-resistant gonorrhea. MMWR Morb Mortal Wkly Rep. 2013;62(6):103-6.

29. Hottes TS, Lester RT, Hoang LM, McKay R, Imperial M, Gilbert $M$, et al. Cephalosporin and azithromycin susceptibility in Neisseria gonorrhoeae isolates by site of infection, British Columbia, 2006 to 2011. Sex Transm Dis. 2013;40(1):46-51. http://dx.doi.org/10.1097/OLQ.obo13e31827bd64C

30. Ison CA, Town K, Obi C, Chisholm S, Hughes G, Livermore DM, et al. Decreased susceptibility to cephalosporins among gonococci: data from the Gonococcal Resistance to Antimicrobials Surveillance Programme (GRASP) in England and Wales, 2007-2011. Lancet Infect Dis. 2013;13(9):762-8. http://dx.doi.org/10.1016/S1473-3099(13)70143-9

31. Bolan GA, Sparling PF, Wasserheit JN. The emerging threat of untreatable gonococcal infection. N Engl J Med. 2012;366(6):485-7. http://dx.doi.org/10.1056/NEJMp1112456

32. Goldstein E, Kirkcaldy RD, Reshef D, Berman S, Weinstock $\mathrm{H}$, Sabeti $\mathrm{P}$, et al. Factors related to increasing prevalence of resistance to ciprofloxacin and other antimicrobial drugs in Neisseria gonorrhoeae, United States. Emerg Infect Dis. 2012;18(8):1290-7. http://dx.doi.org/10.3201/eid1808.111202

33. European Centre for Disease Prevention and Control. Response plan to control and manage the threat of multidrug-resistant gonorrhoea in Europe. Stockholm: ECDC, 2012. [Accessed 21 Aug 2014]. Available from: http://www.ecdc.europa.eu/ en/publications/Publications/1206-ECDC-MDR-gonorrhoearesponse-plan.pdf 